\title{
Risk factors for postoperative respiratory complications following esophageal cancer resection
}

\author{
ATSUSHI SHIOZAKI, HITOSHI FUJIWARA, HIROKO OKAMURA, YASUTOSHI MURAYAMA, \\ SHUHEI KOMATSU, YOSHIAKI KURIU, HISASHI IKOMA, MASAYOSHI NAKANISHI, DAISUKE ICHIKAWA, \\ KAZUMA OKAMOTO, TOSHIYA OCHIAI, YUKIHITO KOKUBA and EIGO OTSUJI
}

Division of Digestive Surgery, Department of Surgery, Kyoto Prefectural University of Medicine, Kamigyo-ku, Kyoto 602-8566, Japan

Received March 8, 2011; Accepted January 26, 2012

DOI: $10.3892 / 01.2012 .589$

\begin{abstract}
The development of surgical and postoperative management techniques has improved the treatment outcomes of esophageal cancer resection. However, respiratory morbidity is still the most frequent complication after esophagectomy. The objective of the present study was to identify risk factors for respiratory complications following resection for esophageal cancer. This study included 96 patients with esophageal cancer who had undergone esophagectomy with lymph node dissection. The patients were divided into 2 groups according to the presence ( 20 patients, 17 had pneumonia and 3 had acute respiratory distress syndrome) or absence (76 patients) of postoperative respiratory complications (PRC). The two groups were compared with respect to their preoperative clinical variables, such as age, body mass index, smoking history, serum albumin, serum C-reactive protein (CRP), number of lymphocytes, \%VC, FEV1.0\% and FEV1.0. Furthermore, multiple logistic regression analyses were used to estimate relative risk factors for respiratory complications. Results of the univariate analysis showed that smoking history $(+/-$, patients with PRC, 19/1 and without PRC, 53/23), serum CRP ( $\geq 1.0 \mathrm{mg}$ / $\mathrm{dl} /<1.0 \mathrm{mg} / \mathrm{dl}$, patients with PRC, 6/14 and without PRC, 6/70) and FEV1.0\% $(\geq 60 \% /<60 \%$, patients with PRC, $16 / 4$ and without PRC, 73/3) were significantly different between the two groups. Multiple logistic regression analysis showed that FEV1.0\% was the strongest predictor of PRC. FEV1.0\%, serum $\mathrm{CRP}$ and smoking history are reliable predictors of the risk of respiratory complications following esophageal cancer resection. For patients with these factors, perioperative management for the prevention of postoperative respiratory complications should be considered.
\end{abstract}

Correspondence to: Dr Atsushi Shiozaki, Division of Digestive Surgery, Department of Surgery, Kyoto Prefectural University of Medicine, 465 Kajii-cho, Kamigyo-ku, Kyoto 602-8566, Japan E-mail: shiozaki@koto.kpu-m.ac.jp

Key words: postoperative respiratory complication, esophageal cancer

\section{Introduction}

Radical esophagectomy is the primary curative therapy for patients with esophageal cancer, and recent progress in surgical and postoperative management techniques has improved treatment outcomes (1). However, esophageal resection is associated with considerable morbidity and mortality. In particular, respiratory morbidity remains the most common serious complication after esophagectomy (2-4), and the incidence of major respiratory complications can reach $30 \%$ or higher, even in experienced centers, although results of a number of reports have shown a respiratory complication rate of approximately $20 \%$ (5).

The surgical trauma caused by esophagectomy is greater than that caused by any other general surgical operations. It often involves the abdomen, chest, and neck, and it may cause postoperative respiratory complications and postoperative immune depression, resulting in the inhibition of host immunity against postoperative infections (6). In addition, postoperative dysfunction of the respiratory muscles and recurrent laryngeal nerve injury lead to a high pulmonary risk of respiratory complications after esophagectomy (7). Furthermore, patients with esophageal cancer are often heavy smokers, consume large quantities of alcohol, and suffer from chronic diseases. The majority of these patients are also malnourished as a result of reduced food intake due to malignant stenosis. Advanced age, abnormal lung function, and poor performance status are reported to contribute to postoperative pulmonary complications $(3,4,8)$.

Prediction of postoperative respiratory complications using preoperative data of patients is crucial in preventing such complications. The objective of the present study was to identify risk factors for respiratory complications following resection for esophageal cancer using preoperative clinical parameters, such as age, body mass index, smoking history, blood biochemical parameters, and respiratory function.

\section{Patients and methods}

Patients and clinicopathologic parameters. The present study included 96 patients with esophageal cancer who had undergone right transthoracic esophagectomy with extensive 
lymph node dissection at the Division of Digestive Surgery, Department of Surgery, Kyoto Prefectural University of Medicine between 2007 and 2009. The patients were divided into 2 groups according to the presence (20 patients) or absence (76 patients) of postoperative respiratory complications.

The 2 groups were compared with respect to their clinicopathological parameters, such as T, N, M categories; pathological stage; curativity; thoracic approach; and preoperative therapies. Histopathological examinations were performed on the primary lesions and all dissected lymph nodes using serial sections. All histopathological diagnoses were performed by experienced pathologists. T, N, M categories and pathological stage were classified according to the pTNM Pathological Classification (UICC International Union Against Cancer TNM Classification of Malignant Tumours; 7th edition) (9). Curativity was classified according to the Japanese Guidelines for Clinical and Pathologic Studies on Carcinoma of the Esophagus (10th edition) (10). With respect to the surgical thoracic approach, 76 patients underwent thoracotomy, while 20 patients underwent thoracoscopic surgery (11). A total of 43 patients received preoperative chemotherapy with cisplatin plus 5-fluorouracil. Of the 43 patietns, 16 underwent preoperative radiotherapy involving a total of $40.0 \mathrm{~Gy}$.

To determine effective predictors of postoperative respiratory complications, the 2 groups were compared with respect to their preoperative clinical parameters, such as age, body mass index, smoking history, serum albumin, serum C-reactive protein (CRP), number of lymphocytes, percentage vital capacity (\%VC), FEV1.0\%, and forced expiratory volume in one second (FEV1.0). Furthermore, multiple logistic-regression analyses were used to estimate relative risk factors.

The study was approved by the institutional review board. Written informed consent was obtained from all patients.

Statistical analysis. Statistical analysis was carried out using the Student's t-test and Fisher's exact test for clinicopathological characteristics and preoperative clinical parameters. Multiple logistic regression was used to identify risk factors associated with postoperative respiratory complications. Differences were considered significant when $\mathrm{p}<0.05$. These analyses were performed electronically using statistical software (JMP, version 5).

\section{Results}

Respiratory management following surgery. The 96 patients included in this study were divided into 2 groups according to the presence (20 patients) or absence ( 76 patients) of postoperative respiratory complications. Postoperative respiratory complications occurred in $20.8 \%$ patients, of whom, 17 patients had pneumonia, and 3 patients had acute respiratory distress syndrome (ARDS) (Table I). No significant differences were found between the two groups with regards to clinicopathological background, such as T, N, M categories; pathological stage; curativity; thoracic approach; or preoperative therapy (Table II). The period of respiratory management following surgery was significantly longer in patients with postoperative respiratory complications ( $3.9 \pm 1.0$ days) in comparison with patients without postoperative respiratory complications (1.3 \pm 0.1 days) (mean \pm SEM) (Fig. 1).
Table I. Postoperative respiratory complications of 96 patients who underwent esophagectomy.

Group No. of cases

Patients with postoperative

respiratory complications

Pneumonia

ARDS

Patients without postoperative 76 respiratory complications

ARDS, acute respiratory distress syndrome.

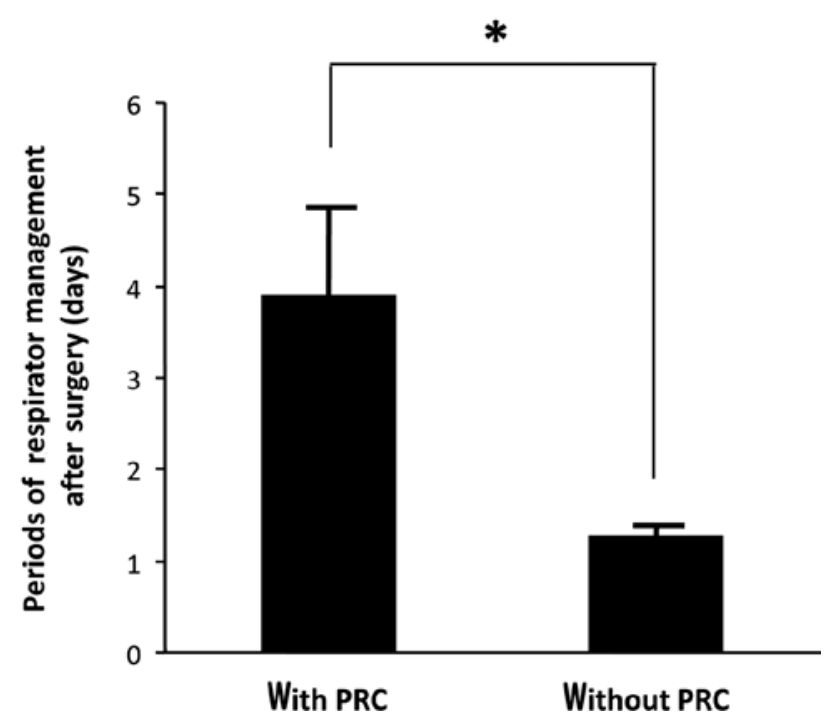

Figure 1. Comparison of the duration of respiratory management following surgery between patients with and without postoperative respiratory complications (PRC). The period of respiratory management after esophagectomy was significantly longer in patients with PRC. Mean \pm SEM. ${ }^{*} \mathrm{P}<0.05$ was considered to indicate a statistically significant result.

Preoperative clinical parameters for patients with and without postoperative respiratory complications. To determine effective predictors of postoperative respiratory complications, we compared the 2 groups with respect to preoperative clinical parameters, such as age, body mass index, smoking history, serum albumin, serum CRP, number of lymphocytes, and the results of conventional respiratory function tests $(\% \mathrm{VC}$, FEV1.0\% and FEV1.0) (Table III). The patients with and without postoperative respiratory complications did not differ significantly with respect to age, body mass index, serum albumin, number of lymphocytes, \%VC or FEV1.0. Results of the univariate analysis showed that smoking history, serum CRP and FEV1.0\% were significantly different between the two groups. A history of smoking was noted in 19 of 20 patients with postoperative respiratory complications $(95.0 \%)$ and 53 of 76 patients without complications $(69.7 \%)(\mathrm{p}=0.021)$. With respect to serum CRP, a level of $\geq 1.0 \mathrm{mg} / \mathrm{dl}$ was detected in $30.0 \%$ of patients with postoperative respiratory complications and in $7.9 \%$ of patients without complications $(\mathrm{p}=0.016)$. With respect to FEV1.0\%, $20.0 \%$ of patients with and $3.9 \%$ of 
Table II. Comparison of clinicopathological backgrounds between patients with and without postoperative respiratory complications.

\begin{tabular}{|c|c|c|c|}
\hline \multirow[t]{2}{*}{ Variables } & \multicolumn{2}{|c|}{ No. of cases } & \multirow[t]{2}{*}{$\mathrm{p}$-value } \\
\hline & With PRC & Without PRC & \\
\hline \multicolumn{4}{|l|}{ pT category } \\
\hline pTis-2 & 9 & 45 & 0.314 \\
\hline pT3-4 & 11 & 31 & \\
\hline \multicolumn{4}{|l|}{ pN category } \\
\hline pNO & 6 & 42 & 0.077 \\
\hline $\mathrm{pN} 1-3$ & 14 & 34 & \\
\hline \multicolumn{4}{|l|}{ pM category } \\
\hline $\mathrm{pM} 0$ & 16 & 68 & 0.266 \\
\hline pM1 & 4 & 8 & \\
\hline \multicolumn{4}{|l|}{ Pathological stage } \\
\hline pStage 0-II & 11 & 52 & 0.296 \\
\hline pStage III-IV & 9 & 24 & \\
\hline \multicolumn{4}{|l|}{ Curativity } \\
\hline A & 10 & 48 & 0.313 \\
\hline $\mathrm{BC}$ & 10 & 28 & \\
\hline \multicolumn{4}{|l|}{ Thoracic approach } \\
\hline Thoracotomy & 18 & 58 & 0.229 \\
\hline Thoracoscopic surgery & 2 & 18 & \\
\hline \multicolumn{4}{|l|}{ Preoperative radiotherapy } \\
\hline+ & 3 & 13 & 1.000 \\
\hline- & 17 & 63 & \\
\hline \multicolumn{4}{|c|}{ Preoperative chemotherapy } \\
\hline+ & 8 & 35 & 0.801 \\
\hline- & 12 & 41 & \\
\hline
\end{tabular}

PRC, postoperative respiratory complications.

those without postoperative respiratory complications had an FEV $1.0 \%$ of $<60 \%(\mathrm{p}=0.033)$.

Effect of the presence of postoperative respiratory complications as a dependent variable. Multiple logistic-regression analysis was performed using the presence of postoperative respiratory complications as the dependent variable. Four preoperative clinical parameters, i.e., smoking history, serum albumin, serum CRP, and FEV1.0\%, which showed low p-values $(<0.10)$ in the univariate analysis were used as independent variables. The multiple logistic-regression analysis revealed that FEV1.0\% was the most effective predictor of postoperative respiratory complications $(\mathrm{p}=0.017)$ (Table IV). In addition, serum CRP and smoking history were the second $(p=0.076)$ and third (0.097) most effective predictors of postoperative respiratory complications (Table IV).

\section{Discussion}

Pulmonary complications remain the most common and serious complications after esophagectomy (2-4). Various factors have been suggested to predispose patients to pulmonary morbidity, including advanced age, a history of smoking, cirrhosis, diabetes, an abnormal chest radiograph, lung disease, spirometric or nutritional parameters, blood loss, blood transfusion volume, low serum albumin, adjuvant oncologic therapy, general performance status, inadequate postoperative analgesia, and disease stage $(2,3,5,12-14)$. In the present study, we found FEV1.0\%, serum CRP and smoking history to be effective preoperative predictors of postoperative respiratory complications.

Preoperative pulmonary dysfunction is significantly associated with the development of postoperative pulmonary complications $(4,8,15)$. In general, a poor pulmonary status involving a \% VC of $<80 \%$ and an FEV1.0\% of $<70 \%$ is associated with both pulmonary and non-pulmonary postoperative morbidity (15). In the present study, FEV1.0\% was the most effective predictor of postoperative pulmonary complications, whereas \%VC was not an effective predictor of postoperative pulmonary complications. Avendano et al reported that impaired pulmonary function (in particular an FEV1.0\% of $<65 \%$ ) is associated with prolonged mechanical ventilation and prolonged hospital stay (8). Based on their report, we used an FEV1.0\% value of $65 \%$ as the threshold value and found that FEV1.0\% was a reliable predictor of the risk of respiratory complications following esophageal cancer resection (data not shown). Furthermore, when we used an FEV1.0\% 
Table III. Comparison of preoperative clinical parameters between patients with and without postoperative respiratory complications .

\begin{tabular}{|c|c|c|c|}
\hline \multirow[t]{2}{*}{ Variables } & \multicolumn{2}{|c|}{ Number of cases } & \multirow[t]{2}{*}{ p-value } \\
\hline & With PRC & Without PRC & \\
\hline \multicolumn{4}{|l|}{ Age } \\
\hline$\geq 75$ & 3 & 4 & 0.155 \\
\hline$<75$ years & 17 & 72 & \\
\hline \multicolumn{4}{|c|}{ Body mass index } \\
\hline$\geq 25$ & 3 & 5 & 0.357 \\
\hline$<25$ & 17 & 71 & \\
\hline \multicolumn{4}{|c|}{ Smoking history } \\
\hline+ & 19 & 53 & $0.021^{\mathrm{a}}$ \\
\hline- & 1 & 23 & \\
\hline \multicolumn{4}{|c|}{ Serum albumin (g/dl) } \\
\hline$\geq 3.8$ & 12 & 62 & 0.070 \\
\hline$<3.8$ & 8 & 14 & \\
\hline \multicolumn{4}{|c|}{ Serum CRP (mg/dl) } \\
\hline$\geq 1.0$ & 6 & 6 & $0.016^{\mathrm{a}}$ \\
\hline$<1.0$ & 14 & 70 & \\
\hline \multicolumn{4}{|c|}{ Number of lymphocytes $\left(/ \mathrm{mm}^{2}\right)$} \\
\hline$\geq 1500$ & 11 & 51 & 0.431 \\
\hline$<1500$ & 9 & 25 & \\
\hline \multicolumn{4}{|l|}{$\% \mathrm{VC}$} \\
\hline$\geq 70$ & 19 & 74 & 0.508 \\
\hline$<70$ & 1 & 2 & \\
\hline \multicolumn{4}{|l|}{ FEV $1.0 \%$} \\
\hline$\geq 60$ & 16 & 73 & $0.033^{\mathrm{a}}$ \\
\hline$<60$ & 4 & 3 & \\
\hline \multicolumn{4}{|l|}{ FEV1.0 } \\
\hline$\geq 1.51$ & 19 & 73 & 1.000 \\
\hline$<1.51$ & 1 & 3 & \\
\hline
\end{tabular}

PRC, postoperative respiratory complications; $\mathrm{CRP}, \mathrm{C}$-reactive protein; $\mathrm{FEV}$, forced expiratory volume. ${ }^{\mathrm{a}} \mathrm{P}<0.05$ was considered to indicate a statistically significant difference.

value of $60 \%$ as the threshold value, FEV1.0\% proved to be the strongest predictor. Thus, an FEV1.0\% threshold value of $<60 \%$ appears to be the most sensitive and effective predictive factor of pulmonary complications after esophagectomy in clinical practice.

On the basis of these results, it is crucial to plan perioperative management to prevent postoperative respiratory complications caused by esophageal surgery (16). In the present study, FEV1.0\% was found to be the most effective predictor of postoperative respiratory complications. In several randomized controlled trials, the efficacy of preoperative rehabilitation to improve the activity of the respiratory muscles and thoracic compliance has been investigated $(17,18)$. Chumillas et al reported the result of a single blind randomized clinical trial of 81 patients following upper abdominal surgery and showed that the incidence of postoperative pulmonary complications was $7.5 \%$ in the rehabilitation group and $19.5 \%$ in the control group (18). Recently, the introduction of enhanced recovery after surgery (ERAS) protocols has revolutionized preoperative and postoperative care $(19,20)$. Evidence suggests that these methods are associated with a reduced hospital stay and minimal morbidity, without affecting patient care, particularly in patients undergoing colorectal surgery (19). Similarly, in esophageal cancer, we believe that the availability of the ERAS protocol, including respiratory rehabilitation, affects postoperative outcomes.

In the present study, we have reported that preoperative serum CRP is a reliable predictor of the risk of respiratory complications following esophagectomy. Elevated serum CRP levels have been shown to be associated with disease progression and poor prognosis in patients with esophageal cancer, and preoperative serum CRP levels have been shown to be an independent prognostic factor in patients with resectable esophageal cancer $(21,22)$. In the present study, we also performed a multiple logistic-regression analysis with serum CRP- and tumor progression-related factors, such as the 
Table IV. Results of the multiple logistic regression analysis using the presence of postoperative respiratory complications as the dependent variable.

\begin{tabular}{|c|c|c|c|c|c|}
\hline Independent variables & Estimate & Standard error & Odds ratio & $95 \% \mathrm{CI}$ & p-value \\
\hline \multicolumn{6}{|l|}{ Smoking history } \\
\hline+ & 0.903 & 0.544 & 2.468 & $0.850-7.172$ & 0.097 \\
\hline \multicolumn{6}{|l|}{-} \\
\hline \multicolumn{6}{|l|}{ Serum albumin $(\mathrm{g} / \mathrm{dl})$} \\
\hline$<3.8$ & 0.400 & 0.350 & 1.491 & $0.751-2.960$ & 0.253 \\
\hline$\geq 3.8$ & & & & & \\
\hline \multicolumn{6}{|l|}{ Serum CRP (mg/dl) } \\
\hline$\geq 1.0$ & 0.706 & 0.398 & 2.025 & $0.929-4.415$ & 0.076 \\
\hline$<1.0$ & & & & & \\
\hline \multicolumn{6}{|l|}{ FEV1.0\% } \\
\hline$<60$ & 1.028 & 0.432 & 2.800 & $1.199-6.521$ & $0.017 *$ \\
\hline$\geq 60$ & & & & & \\
\hline
\end{tabular}

CRP, C-reactive protein; FEV, forced expiratory volume; CI, confidence interval. ${ }^{a} \mathrm{P}<0.05$ was considered to indicate a statistically significant difference.

T, N, M categories and pathological stage, as independent variables and found that serum CRP was the most effective factor. This finding suggested that the serum CRP level itself is an independent predictor of respiratory complications, regardless of the tumor volume (data not shown). Although the clinicopathological significance of this result remains unclear, we consider that the preoperative serum CRP level may reflect basal host immunity, which can be affected by postoperative infection or inflammation.

Our results regarding preoperative serum CRP suggest the importance of perioperative chemical mediator modulation therapy using chemical agents, such as steroids and neutrophil elastase inhibitor (NEI). Steroids directly attenuate surgical stress-induced inflammatory responses by suppressing the release of proinflammatory cytokines, such as IL-6. The use of steroids during the perioperative period following esophagectomy is effective at blocking this inflammatory cascade and preventing postoperative complications $(23,24)$. Sato et al reported that steroid use significantly reduces the incidence of postoperative pneumonia (23). Furthermore, the efficacy of NEI, a selective inhibitor of neutrophil elastase, used for preventing postoperative pneumonia in esophagectomies has been evaluated $(25,26)$. Suda et al concluded that the duration of postoperative SIRS after esophagectomy, the duration of mechanical ventilation, and the length of ICU stay were significantly shortened in NEI-treated patients (25). In their study, Ono et al reported that the preventive administration of NEI reduced the rate of postoperative SIRS in patients with severe conditions on mechanical ventilation after esophagectomy (26). For patients that exhibit an elevated preoperative serum CRP level, perioperative chemical mediator modulation using these agents may be effective at preventing postoperative respiratory complications.

Smoking is a high-risk factor for cardiopulmonary postoperative complications $(4,27)$. The relative risk of complications after surgery for smokers is increased from 1.4-to 4.3-fold in comparison with non-smokers $(28,29)$. In the present study, smoking history was an effective predictor of postoperative pulmonary complications, suggesting the importance of smoking cessation. Bluman et al reported that the incidence of postoperative pulmonary complications is $22.0 \%$ in current smokers, $12.8 \%$ in past smokers, and $4.9 \%$ in patients who have never smoked, respectively (30). Barrera et al evaluated 300 patients who had undergone thoracic surgery and divided them into 4 groups: non-smokers, past quitters (who stopped smoking $>2$ months ago), recent quitters (who stopped $>1$ week ago and $\leq 2$ months ago) and current smokers (31). The incidence of postoperative pneumonia was significantly different between the non-smokers and the smokers in the 4 groups, (3, 10,15 , and $23 \%$, respectively). In the present study, we were not able to analyze the duration of smoking cessation in detail due to insufficient smoking data. However, based on these reports, we recommended that smoking should be ceased for at least 1 month prior to esophagectomy.

In conclusion, the present study investigated the relationship between the preoperative parameters and postoperative pulmonary complications in detail. The results showed that FEV 1.0\%, serum CRP and smoking history are reliable predictors of the risk of respiratory complications following esophageal cancer resection. Thus, our findings suggest that perioperative management for the prevention of postoperative respiratory complications should be planned on the basis of these predictors.

\section{References}

1. Tachibana M, Kinugasa S, Yoshimura H, Shibakita M, Tonomoto Y, Dhar DK and Nagasue N: Clinical outcomes of extended esophagectomy with three-field lymph node dissection for esophageal squamous cell carcinoma. Am J Surg 189: 98-109, 2005.

2. Whooley BP, Law S, Murthy SC, Alexandrou A and Wong J: Analysis of reduced death and complication rates after esophageal resection. Ann Surg 233: 338-344, 2001. 
3. Law S, Wong KH, Kwok KF, Chu KM and Wong J: Predictive factors for postoperative pulmonary complications and mortality after esophagectomy for cancer. Ann Surg 240: 791-800, 2004.

4. Ferguson MK and Durkin AE: Preoperative prediction of the risk of pulmonary complications after esophagectomy for cancer. J Thorac Cardiovasc Surg 123: 661-669, 2002.

5. Bailey SH, Bull DA, Harpole DH, Rentz JJ, Neumayer LA, Pappas TN, Daley J, Henderson WG, Krasnicka B and Khuri SF: Outcomes after esophagectomy: a ten-year prospective cohort. Ann Thorac Surg 75: 217-222, 2003.

6. van Sandick JW, Gisbertz SS, ten Berge IJ, Boermeester MA, van der Pouw Kraan TC, Out TA, Obertop H and van Lanschot JJ: Immune responses and prediction of major infection in patients undergoing transhiatal or transthoracic esophagectomy for cancer. Ann Surg 237: 35-43, 2003.

7. Hulscher JB, van Sandick JW, Devriese PP, van Lanschot JJ and Obertop H: Vocal cord paralysis after subtotal oesophagectomy. Br J Surg 86: 1583-1587, 1999.

8. Avendano CE, Flume PA, Silvestri GA, King LB and Reed CE: Pulmonary complications after esophagectomy. Ann Thorac Surg 73: 922-926, 2002.

9. Sobin L, Gospodarowicz M, Wittekind C, (eds.). TNM Classification of Malignant Tumors. 7th edition. John Wiley \& Sons, Inc., Hoboken, 2009

10. Japanese Society for Esophageal Disease: Guidelines for the Clinical and Pathologic Studies on Carcinoma of the Esophagus, 10th edition. Kanehara Co. Ltd., Tokyo, 2008.

11. Osugi H, Takemura M, Lee S, Nishikawa T, Fukuhara K, Iwasaki $\mathrm{H}$ and Higashino M: Thoracoscopic esophagectomy for intrathoracic esophageal cancer. Ann Thorac Cardiovasc Surg 11: 221-227, 2005.

12. Atkins BZ, Shah AS, Hutcheson KA, Mangum JH, Pappas TN, Harpole DH Jr and D'Amico TA: Reducing hospital morbidity and mortality following esophagectomy. Ann Thorac Surg 78: 1170-1176, 2004

13. Viklund P, Lindblad M, Lu M, Ye W, Johansson J and Lagergren J: Risk factors for complications after esophageal cancer resection: a prospective population-based study in Sweden. Ann Surg 243: 204-211, 2006

14. Grotenhuis BA, Wijnhoven BP, Grüne F, van Bommel J, Tilanus HW and van Lanschot JJ: Preoperative risk assessment and prevention of complications in patients with esophageal cancer. J Surg Oncol 101: 270-278, 2010.

15. Kuwano H, Sumiyoshi K, Sonoda K, Kitamura K, Tsutsui S, Toh Y, Kitamura M and Sugimachi K: Relationship between preoperative assessment of organ function and postoperative morbidity in patients with oesophageal cancer. Eur J Surg 164 : 581-586, 1998

16. Akutsu Y and Matsubara H: Perioperative management for the prevention of postoperative pneumonia with esophageal surgery. Ann Thorac Cardiovasc Surg 15: 280-285, 2009.

17. Reeve JC, Nicol K, Stiller K, McPherson KM and Denehy L: Does physiotherapy reduce the incidence of postoperative complications in patients following pulmonary resection via thoracotomy? a protocol for a randomized controlled trial. J Cardiothorac Surg 3: 48, 2008.

18. Chumillas S, Ponce JL, Delgado F, Viciano V and Mateu M Prevention of postoperative pulmonary complications through respiratory rehabilitation: a controlled clinical study. Arch Phys Med Rehabil 79: 5-9, 1998.
19. Walter CJ, Collin J, Dumville JC, Drew PJ and Monson JR: Enhanced recovery in colorectal resections: a systematic review and meta-analysis. Colorectal Dis 11: 344-353, 2009.

20. Arsalani-Zadeh R, ElFadl D, Yassin N and MacFie J: Evidence-based review of enhancing postoperative recovery after breast surgery. Br J Surg 98: 181-196, 2011.

21. Ikeda M, Natsugoe S, Ueno S, Baba M and Aikou T: Significant host- and tumor-related factors for predicting prognosis in patients with esophageal carcinoma. Ann Surg 238: 197-202, 2003.

22. Fujiwara H, Suchi K, Okamura S, Okamura H, Umehara S, Todo M, Shiozaki A, Kubota T, Ichikawa D, Okamoto K, Ochiai T, Kokuba Y, Sonoyama T and Otsuji E: Elevated serum CRP levels after induction chemoradiotherapy reflect poor treatment response in association with IL-6 in serum and local tumor site in patients with advanced esophageal cancer. J Surg Oncol 103: 62-68, 2011

23. Sato N, Koeda K, Ikeda K, Kimura Y, Aoki K, Iwaya T, Akiyama Y, Ishida K, Saito K and Endo S: Randomized study of the benefits of preoperative corticosteroid administration on the postoperative morbidity and cytokine response in patients undergoing surgery for esophageal cancer. Ann Surg 236: 184-190, 2002.

24. Tsukada K, Miyazaki T, Katoh H, Masuda N, Fukuchi M, Manda R, Fukai Y, Nakajima M, Sohda M, Kimura H and Kuwano H: Effect of perioperative steroid therapy on the postoperative course of patients with oesophageal cancer. Dig Liver Dis 38: 240-244, 2006.

25. SudaK,Kitagawa Y, Ozawa S, Miyasho T, Okamoto M, Saikawa Y, Ueda M, Yamada S, Tasaka S, Funakoshi Y, Hashimoto S, Yokota H, Maruyama I, Ishizaka A and Kitajima M: Neutrophil elastase inhibitor improves postoperative clinical courses after thoracic esophagectomy. Dis Esophagus 20: 478-486, 2007.

26. Ono S, Tsujimoto H, Hiraki S, Takahata R, Kimura A, Kinoshita M, Ichikura T and Mochizuki H: Effects of neutrophil elastase inhibitor on progression of acute lung injury following esophagectomy. World J Surg 31: 1996-2001, 2007.

27. Schwilk B, Bothner U, Schraag S and Georgieff M: Perioperative respiratory events in smokers and nonsmokers undergoing general anaesthesia. Acta Anaesthesiol Scand 41: 348-355, 1997.

28. Wetterslev J, Hansen EG, Kamp-Jensen M, Roikjaer O and Kanstrup IL. PaO2 during anaesthesia and years of smoking predict late postoperative hypoxaemia and complications after upper abdominal surgery in patients without preoperative cardiopulmonary dysfunction. Acta Anaesthesiol Scand 44: $9-16,2000$

29. Smetana GW: Preoperative pulmonary evaluation. N Engl J Med 340: 937-944, 1999.

30. Bluman LG, Mosca L, Newman N and Simon DG: Preoperative smoking habits and postoperative pulmonary complications. Chest 113: 883-889, 1998.

31. Barrera R, Shi W, Amar D, Thaler HT, Gabovich N, Bains MS and White DA: Smoking and timing of cessation: impact on pulmonary complications after thoracotomy. Chest 127 : 1977-1983, 2005. 